attractive possibility is an extended circumlunar flight in a polar orbit lasting 28 days so that all the Moon is covered by the astronauts. NASA is also committed to the Apollo application programme, which Dr Paine sees as the prototype of a space station which could be started in, say, 1975, and be gradually built up over a period of a decade to hold fifty astronauts.

The ten flights to the Moon will decide whether further trips would be useful and whether a lunar station would be worthwhile. By then the United States may be deciding on a manned expedition to Mars, which Dr Paine thought could take place in about 1985. But it looks as if the United States is not going to be stampeded into a trip to Mars in the same way as the Moon expedition came about. NASA is sending a series of probes to Mars to see whether a manned mission would be valuable. Two Mariners are to make a close approach to the planet, with television pictures, on July 31 and August 6 .

\section{ROYAL SOCIETY}

\section{Cook Bicentenury}

THe Royal Society on Tuesday this week celebrated the observations of the transit of Venus across the Sun by Captain Cook from Tahiti on June 3, 1769. Plainly the society is proud of the sea captain with a passion for navigation and measurement who literally and in every other sense put a large part of Australasia on the map. The celebrations this week seemed accurately to convey the sense that it is entirely proper for the Royal Society to mark this old feat of navigation even though academies elsewhere are more deeply involved in celebrating navigation to the Moon and other places now as obscure as what are known as the Antipodes used to be.

Lord Blackett, president of the society, and himself once a naval officer, made it clear that Captain Cook would not be forgotten. Sir Richard Woolley, Astronomer Royal, provided a splendid ten minute sketch of the importance of the observation of the transit of Venus from Tahiti two hundred years ago, with accurate navigation only just possible because of the development of an accurate chronometer-Kendall's first copy of the watch with which Harrison won the prize for a chronometer was proudly shown on Tuesday. The object of the observation of the time taken for Venus to cross the distance of the Sun was to derive an accurate value for the solar parallax. The point is that observations from two latitudes can be combined together to produce a value of some sort, as Halley pointed out in 1716. Sir Richard Woolley explained why the transit of Venus in 1761 had yielded nothing useful-there had been incomplete measurements from a southern latitude, partly at least because of the fecklessness of Messrs Mason and Dixon, the freelance surveyors, now commemorated by the Mason-Dixon line in the United States, but then, in February 1761, scolded by the Royal Society for lack of persistence.

Cook was a different fellow and found his way efficiently to Tahiti. Sir Richard Woolley was at pains on Tuesday to rehabilitate the reputation of this expedition, for many years in disrepute on the grounds that the value of the solar parallax eventually obtained was too far from the truth. He pointed out that Simon Newcombe, in the nineteenth century, had used Cook's observations to obtain values not very different from 8.794 seconds of arc, afterwards accepted. To be sure, it is no longer necessary to wait for the transit of Venus to make this measurement, but even so, there will no doubt be more than sentimental interest in the next transit of Venus in AD 2004.

\section{INFRARED ASTRONOMY \\ Further Infrared}

\section{from our Astronomy Correspondent}

WITH the design complete of the 60-inch infrared telescope to be built at Imperial College, London, Professor J. Ring, who leads the infrared team is looking forward to the 120-inch telescope which is the logical next step. Experience gained with the 60-inch, which will be one of the largest telescopes purely for infrared work, will be used in the design study for the 120 -inch. So far, however, the team at Imperial College has money only for the smaller telescope, $£ 27,000$ awarded earlier this year by the Science Research Council (Nature, 221, 214; 1969). A start has nevertheless been made on testing suitable sites for an observatory, and the island of Tenerife in the Canaries

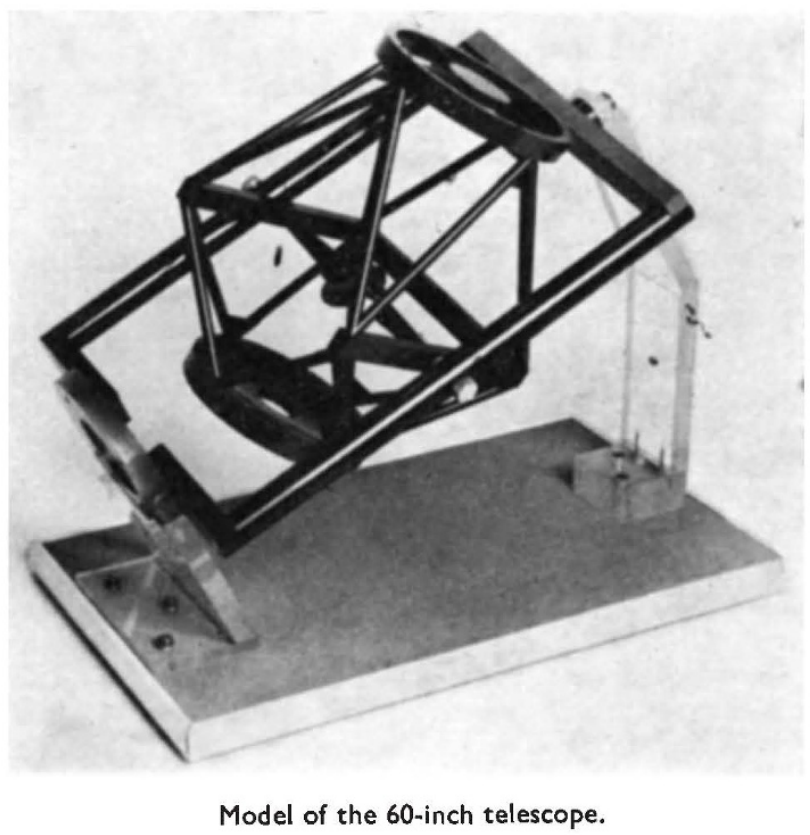

still seems to be hot favourite. The intention is to have the 60 -inch telescope built and fully installed by late 1970 .

Although an equatorial mounting has been chosen for the 60 -inch, the 120 -inch may have a different system. One possibility is the increasingly fashionable altazimuth mounting, with one axis of rotation horizontal and the other vertical, which has the advantage that for a given altitude direction, the stress on the telescope (especially the mirror) is the same for all azimuths. The problem of keeping altazimuth instruments trained on a particular star has now been overcome by computer-a suitable small computer would cost less than $£ 10,000$. Several other more or less bizarre new mounting systems are being considered, and Professor Ring hopes that by the end of the year the choice will be narrowed down to one or two. "The 